CLINICAL STUDY

\title{
Subclinical hyperthyroidism and blood pressure in a population- based prospective cohort study
}

\author{
Henry Völzke ${ }^{1, *}$, Till Ittermann ${ }^{1, *}$, Carsten O Schmidt ${ }^{1}$, Marcus Dörr ${ }^{2}$, Ulrich John ${ }^{3}$, Henri Wallaschofski ${ }^{2}$, \\ Bruno H C Stricker ${ }^{4}$, Stephan B Felix ${ }^{2}$ and Rainer Rettig ${ }^{5}$ \\ ${ }^{1}$ SHIP/Clinical-Epidemiological Research Unit, Institute of Community Medicine, ${ }^{2}$ Department of Medicine and ${ }^{3}$ Institute of Epidemiology and Social \\ Medicine, Ernst Moritz Arndt University of Greifswald, Walther Rathenau Strasse 48, D-17487 Greifswald, Germany, ${ }^{4}$ Institute of Epidemiology and \\ Biostatistics, Erasmus University Rotterdam, NL 3000 DR Rotterdam, The Netherlands and ${ }^{5}$ Institute of Physiology, Ernst Moritz Arndt University of \\ Greifswald, Walther Rathenau Strasse 48, D-17487 Greifswald, Germany
}

(Correspondence should be addressed to H Völzke; Email: voelzke@uni-greifswald.de)

*(H Völzke and T Ittermann contributed equally to this work)

\begin{abstract}
Objectives: There is current controversy on the association between subclinical hyperthyroidism and hypertension. Data from cohort studies have not been available yet. The present study was designed to longitudinally investigate possible associations of subclinical hyperthyroidism with blood pressure, pulse pressure and the risk of hypertension.

Methods: We used data from the population-based, prospective cohort Study of Health in Pomerania and included 2910 subjects (1469 women) aged 20-79 years with completed 5-year examination follow-up. Subjects with increased serum TSH levels or overt hyperthyroidism were excluded. Serum TSH levels below $0.25 \mathrm{mIU} / \mathrm{l}$ with free triiodothyronine and free thyroxine levels within the reference range were defined as subclinical hyperthyroidism. Blood pressure was measured according to standard methods.

Results: Multivariable analyses adjusted for age, sex, overweight, obesity, smoking status and time between the examinations did not reveal any statistically significant association between subclinical hyperthyroidism and any of the blood pressure-related variables in the whole study population. Although the 5-year hypertension incidence was higher in subjects with subclinical hyperthyroidism compared with those without (31.4 vs $19.2 \%$; risk ratio 1.64 ; $95 \%$ confidence interval (CI) 1.17-2.28, $P=0.006)$, both groups did not differ with respect to the risk of hypertension, after analyses were adjusted for confounders (relative risk 1.23, 95\% CI 0.91-1.68, P=0.182). Analyses yielded similar results in subjects without thyroid disease and in those who took no antihypertensive medication. Conclusion: Subclinical hyperthyroidism is not associated with changes in blood pressure, pulse pressure or incident hypertension.
\end{abstract}

European Journal of Endocrinology 161 615-621

\section{Introduction}

The role of subclinical hyperthyroidism in cardiovascular disorders is a matter of debate and subject to ongoing controversy. Several previous studies found associations of subclinical hyperthyroidism with cardiovascular disorders such as endothelial dysfunction (1), left ventricular hypertrophy (2), thickened artery walls (3) or atrial fibrillation (4). The cardiovascular disorders associated with subclinical hyperthyroidism may be a direct effect of thyroid hormone disturbance. Alternatively, they may reflect an increased arterial pressure level in subjects with subclinical hyperthyroidism.

In the past few years, several population-based studies (5-7) have investigated the association of subclinical hyperthyroidism with blood pressure and hypertension. One of these studies (5) demonstrated that subjects with subclinical hyperthyroidism had a 2.8-fold (95\% confidence interval (CI) 1.3-6.0) increased risk of hypertension compared with euthyroid subjects. Other studies $(6,7)$, however, did not find such an association.

A common drawback of all previous studies on the association of thyroid function with blood pressure and hypertension (5-7) is their cross-sectional design, which makes them prone to false conclusions regarding the sequence of cause and effect. The demonstration of a longitudinal relation between subclinical hyperthyroidism and high blood pressure would be of high relevance for the ongoing discussion on whether subclinical hyperthyroidism should be treated and at what serum TSH level this treatment should be initiated $(8,9)$.

Therefore, the present study was designed to investigate whether subclinical hyperthyroidism 
is associated with increased blood pressure, pulse pressure and the risk of hypertension 5 years later. The study is based on data from a sample of a general adult population with prospective 5-year follow-up examinations.

\section{Methods}

\section{Setting and study population}

The Study of Health in Pomerania (SHIP) is a population-based study conducted in West Pomerania, the north-east area of Germany (10). The study region is a previously iodine-deficient area. Voluntary iodine fortification substantially added to a stable and adequate iodine supply in the study area since the middle of the 1990s (11).

For the baseline examinations, a sample of 6267 eligible subjects aged 20-79 years was drawn from population registries. Only individuals with German citizenship and main residency in the study area were included. Selected persons received a maximum of three written invitations. In the case of non-response, letters were followed by a phone call or by home visits if contact by phone was not possible. The SHIP population finally comprised 4310 participants (response 68.8\%). The study was monitored by a review board of independent scientists. Baseline examinations were conducted between 1997 and 2001. Between 2002 and 2006, all participants were reinvited for an examination follow-up, in which 3300 subjects $(83.5 \%$ of still living and achievable persons) took part $(12,13)$. All participants gave informed written consent. The study protocol is consistent with the principles of the Declaration of Helsinki and was approved by the Ethics Committee of the University of Greifswald.

Among the 3300 participants, there were 106 subjects (65 women), who had missing values in one or more of the considered variables, and 284 participants (177 women) who had increased serum TSH levels or overt hyperthyroidism as defined by serum TSH levels below the lower reference range and free triiodothyronine $\left(\mathrm{FT}_{3}\right)$ or free thyroxine $\left(\mathrm{FT}_{4}\right)$ levels above their upper reference limits. These 390 individuals (242 women) were excluded from further analysis. This resulted in a final study population of 2910 subjects (1469 women) who were available for the present study. The median follow-up time was 5 years (15 284 person-years).

\section{Assessments}

Socio-demographic characteristics, smoking status, parental and medical history of hypertension as well as information on the use of antihypertensive drugs were assessed by computer-assisted personal interviews. After a 5 min rest period, heart rate as well as systolic and diastolic blood pressure was measured thrice at the right arm of seated subjects using a digital blood pressure monitor (HEM-705CP, Omron Corporation, Tokyo, Japan), with each reading being followed by a further rest period of $3 \mathrm{~min}$. The mean of the second and third measurements was calculated and used for the present analyses. Systolic and diastolic blood pressures of $\geq 140$ and $\geq 90 \mathrm{mmHg}$ respectively were considered as an increase. Pulse pressure was defined as the difference between mean systolic and diastolic pressures. Increased pulse pressure was present if values were above the 75 th percentile of the pulse pressure distribution. Hypertension was defined as increased systolic or diastolic blood pressure or use of antihypertensive medication. Height and weight were measured for the calculation of the body mass index $\left(\mathrm{BMI}=\right.$ weight $(\mathrm{kg}) /$ height $\left.^{2}\left(\mathrm{~m}^{2}\right)\right)$. Overweight was defined as BMI values $\geq 25 \mathrm{~kg} / \mathrm{m}^{2}$ and obesity as BMI values $\geq 30 \mathrm{~kg} / \mathrm{m}^{2}$.

Blood samples were taken and laboratory parameters were analyzed in one central laboratory. In the baseline SHIP investigations, serum TSH levels were analyzed by an immunochemiluminescent procedure (LIA-mat, Byk Sangtec Diagnostica GmbH, Frankfurt, Germany). The functional sensitivity of the assay was $0.03 \mathrm{mIU} / \mathrm{l}$. The reference range recently established for the SHIP region was $0.25-2.12 \mathrm{mIU} / \mathrm{l}$ (14). In the follow-up investigation, serum TSH levels were also analyzed by an immunochemiluminescent method (Immulite 2000, Third Generation, Diagnostic Products Corporation (DPC), Los Angeles, CA, USA). Method comparison of the DPC method against the Byk-Sangtec method yielded a high correlation coefficient $(r=0.97)$ and revealed a regression equation, according to Passing-Bablok, of $y=1.029 * \times-0.032 \mathrm{mU} / \mathrm{l}(15)$. All serum TSH levels from the follow-up investigation were corrected using this formula. At baseline, serum $\mathrm{FT}_{3}$ (LUMItest, Brahms, Berlin, Germany) and $\mathrm{FT}_{4}$ levels (Byk Sangtec Diagnostica $\mathrm{GmbH}$ ) were measured by immunochemiluminescent procedures. Serum TSH levels below $0.25 \mathrm{mIU} / \mathrm{l}$ with $\mathrm{FT}_{3}$ and $\mathrm{FT}_{4}$ within the reference range $\left(\mathrm{FT}_{3} \leq 7.0 \mathrm{pmol} / \mathrm{l}\right.$ and $\left.\mathrm{FT}_{4} \leq 18.9 \mathrm{pmol} / \mathrm{l}\right)$ were defined as subclinical hyperthyroidism.

\section{Statistical analyses}

Categorical data are given as numbers or percentages as indicated; continuous data are given as medians (25th and 75 th percentile). The study population was divided into two groups according to the presence or absence of subclinical hyperthyroidism at baseline. Comparisons between groups were made using $\chi^{2}$ test (nominal data) and Wilcoxon test (continuous data). Comparisons between baseline and follow-up data were made using Wilcoxon signed-rank test. Because the prevalence of hypertension was $>10 \%$ in our study sample, odds ratios would overestimate the relative risk (RR). 
To estimate the RR from multivariable analysis with dichotomous variables as outcome, we performed Poisson regression with Hubert-White s.E.M. (16). Multivariable analysis of covariance was used to investigate the association between thyroid function and the continuously distributed blood pressure variables for the cohort data. Adjusted RRs or point estimates and their 95\% CI were calculated. A value of $P<0.05$ was considered statistically significant. All statistical analyses were performed with SAS 9.1 (SAS Institute, Inc., Cary, NC, USA).

To assess the sensitivity of our results to non-response and dropout, we applied statistical weights. The aim of this approach is to give more weight to subjects whose propensity to drop out of the study is high. The weights accounted for non-response to baseline (SHIP-0) and for dropout to follow-up (SHIP-1) based on sociodemographic and health-related variables. Robust s.E.M. were computed for all weighted analyses.

\section{Results}

The median follow-up time was 5 years (15 284 personyears). There were 203 individuals ( $7.0 \%, 109$ women) with subclinical hyperthyroidism at baseline. These subjects were older, had higher BMI values and a higher proportion of overweight individuals than subjects who had normal serum TSH levels. Both groups were similar with respect to gender, smoking status and obesity (Table 1).

In the whole population, the median systolic blood pressure decreased from $134 \mathrm{mmHg}(121 ; 148 \mathrm{mmHg})$ at baseline to $131 \mathrm{mmHg}(118 ; 144 \mathrm{mmHg})$ at followup $(P<0.001)$. Likewise, diastolic blood pressure decreased from $83 \mathrm{mmHg}(76 ; 90 \mathrm{mmHg})$ to 80 (74; $88 \mathrm{mmHg}, \quad P<0.001$ ) and pulse pressure decreased from $50 \mathrm{mmHg}(42 ; 60 \mathrm{mmHg})$ to 48 (40; $58 \mathrm{mmHg}, P<0.001)$. At follow-up, 286 subjects

Table 1 Baseline characteristics according to subclinical hyperthyroidism.

\begin{tabular}{|c|c|c|c|}
\hline & \multicolumn{2}{|c|}{$\begin{array}{c}\text { Subclinical hyperthyroidism at } \\
\text { baseline }\end{array}$} & \multirow[b]{2}{*}{$\boldsymbol{P}^{\mathrm{a}}$} \\
\hline & No $(n=2707)$ & Yes $(n=203)$ & \\
\hline Gender (male) & $1347(49.8 \%)$ & $94(46.3 \%)$ & 0.342 \\
\hline Age (years) & $48(36 ; 60)$ & $59(48 ; 66)$ & $<0.001$ \\
\hline \multicolumn{4}{|c|}{ Cigarette smoking status } \\
\hline Never-smoker & $1090(40.3 \%)$ & 80 (39.4\%) & 0.217 \\
\hline Ex-smoker & $923(34.1 \%)$ & $80(39.4 \%)$ & \\
\hline Current smoker & $694(25.6 \%)$ & $43(21.2 \%)$ & \\
\hline $\begin{array}{l}\text { Body mass index } \\
\left(\mathrm{kg} / \mathrm{m}^{2}\right)\end{array}$ & $26.7(23.7 ; 29.8)$ & $27.2(24.9 ; 29.8)$ & 0.042 \\
\hline Overweight $^{\mathrm{b}}$ & $1748(64.6 \%)$ & $150(73.9 \%)$ & 0.007 \\
\hline Obesity $^{c}$ & $661(24.4 \%)$ & $46(22.7 \%)$ & 0.573 \\
\hline
\end{tabular}

Data are given as numbers (\%) or median (25th and 75th percentile).

${ }^{a} \chi^{2}$ test (nominal data) or Kruskal-Wallis test (interval data).

${ }^{\mathrm{b}}$ Overweight was defined as body mass index $\geq 25 \mathrm{~kg} / \mathrm{m}^{2}$.

${ }^{c}$ Obesity was defined as body mass index $\geq 30 \mathrm{~kg} / \mathrm{m}^{2}$.
Table 2 Blood pressure-related variables according to subclinical hyperthyroidism.

\begin{tabular}{lccc}
\hline & \multicolumn{2}{c}{$\begin{array}{c}\text { Subclinical hyperthy- } \\
\text { roidism at baseline }\end{array}$} & \\
\cline { 2 - 3 } & No $(n=2707)$ & Yes $(n=203)$ & $\boldsymbol{P}^{\mathrm{a}}$ \\
\hline Hypertension & & & \\
No & $1090(40.3 \%)$ & $59(29.1 \%)$ & 0.012 \\
Baseline only & $252(9.3 \%)$ & $20(9.9 \%)$ & \\
Follow-up only & $259(9.6 \%)$ & $27(13.3 \%)$ & \\
Baseline and follow-up & $1106(40.9 \%)$ & $97(47.8 \%)$ & \\
Systolic blood pressure & $133.5(120.5 ;$ & $136.0(123.5 ;$ & 0.059 \\
(mmHg; baseline) & $147.5)$ & $149.5)$ & \\
Increased systolic blood & $1019(37.6 \%)$ & $88(43.4 \%)$ & 0.106 \\
pressure $\geq 140$ mmHg & & & \\
(baseline) & & & \\
Diastolic blood pressure & $82.5(75.5 ;$ & $84.0(77.0 ;$ & 0.446 \\
(mmHg; baseline) & $90.5)$ & $91.0)$ & \\
Increased diastolic blood & $735(27.2 \%)$ & $61(30.1 \%)$ & 0.372 \\
pressure $\geq 90$ mmHg & & & \\
(baseline) & & & \\
Pulse pressure (mmHg; & $49.5(41.5 ;$ & $51.5(42.5 ;$ & 0.053 \\
baseline) & $59.5)$ & $62.5)$ & \\
Increased pulse pressure & $732(27.0 \%)$ & $67(33.0 \%)$ & 0.066 \\
$\quad \geq 59.5^{b}$ mmHg & & & \\
(baseline) & & & \\
\hline
\end{tabular}

Data are given as numbers (\%) or median (25th and 75th percentile).

${ }^{a} \chi^{2}$ test (nominal data) or Kruskal-Wallis test (interval data).

b 75 th percentile of the pulse pressure distribution.

were newly diagnosed as being hypertensive (5-year incidence $19.9 \%$ ). Testing the bivariate association without considering confounding variables, subjects with subclinical hyperthyroidism more often had hypertension than reference subjects (5-year hypertension incidence 31.4 vs $19.2 \%$; risk ratio $1.64 ; 95 \%$ CI 1.17-2.28, $P=0.006)$. Differences between the exposure groups with respect to systolic and diastolic blood pressure or pulse pressure were not statistically significant (Table 2).

We further performed multivariable analyses to study the association between subclinical hyperthyroidism and the progression of blood pressure-related variables (Table 3). We found no statistically significant association between subclinical hyperthyroidism and any of the blood pressure-related variables in the whole study population. For sensitivity analyses, we separated all subjects who reported any prevalent or incident thyroid disease or were on antithyroid medication at baseline or follow-up from our study leaving a disease-free population of 2285 subjects (1041 women). There was also no statistically significant association between subclinical hyperthyroidism and blood pressure-related variables in this subpopulation (Table 3).

To test whether possible misclassification in the exposure variable influenced the results of multivariable analyses, we set the TSH cut-off for the definition of subclinical hyperthyroidism to $<0.1 \mathrm{mIU} / \mathrm{l}$. There were 44 subjects $(1.5 \%, 32$ women) who fulfilled this strict criterion. In Poisson regression analyses, they had a similar risk of hypertension at follow-up (RR 1.67, 95\% 
Table 3 Association of subclinical hyperthyroidism with progression of blood pressure-related variables and incident hypertension.

\begin{tabular}{lll}
\hline & $\begin{array}{l}\text { Whole population } \\
(n=2910)\end{array}$ & $\begin{array}{l}\text { Disease-free population } \\
(n=2285)\end{array}$ \\
\hline$\beta$ (95\% confidence interval) & & $\begin{array}{l}0.17(-2.76 \text { to } 3.10) \\
P=0.909\end{array}$ \\
Systolic blood pressure $(\mathrm{mmHg})$ & $1.39(-0.80$ to 3.58$)$ & $0.42(-0.99$ to 2.39$)$ \\
& $P=0.215$ & $P=0.417$ \\
Diastolic blood pressure $(\mathrm{mmHg})$ & $0.94(-0.32$ to 2.19$)$ & $-0.46(-2.43$ to 1.52$)$ \\
& $P=0.144$ & $P=0.651$ \\
Pulse pressure (mmHg) & $0.49(-1.00$ to 1.99$)$ & $1.09(0.67$ to 1.77$)$ \\
Relative risk (95\% confidence interval) & $P=0.518$ & $P=0.742(n=1414)$ \\
Increased systolic blood pressure $\geq 140 \mathrm{mmHg}$ & & $1.20(0.67$ to 2.16$)$ \\
& $1.19(0.85$ to 1.68$)$ & $P=0.540(n=1654)$ \\
& $P=0.311(n=1803)$ & $1.01(0.66$ to 1.55$)$ \\
Increased diastolic blood pressure $\geq 90 \mathrm{mmHg}$ & $1.05(0.65$ to 1.70$)$ & $0.963(n=1704)$ \\
Increased pulse pressure $\geq 59 \mathrm{mmHg}$ & $P=0.850(n=2114)$ & $1.04(0.65$ to 1.67$)$ \\
& $0.95(0.67$ to 1.34$)$ & $P=0.850(n=1292)$ \\
\hline
\end{tabular}

Analysis of covariance for continuous outcome and Poisson regression for dichotomous outcome, adjusted for age, sex, overweight, obesity, smoking status and time between the examinations. Analyses of covariance were additionally controlled for blood pressures at baseline.

${ }^{a}$ Subjects with prevalent disorder at baseline were excluded from analyses. Numbers of subpopulations are given for each analysis.

CI $0.80-3.49, P=0.173)$ as subjects with serum TSH levels in the reference range. Likewise, analyses of covariance did not reveal a statistically significant association between the exposure variable and any of the outcome variables listed in Table 3.

We further repeated all multivariable analyses outlined in Table 3 after exclusion of subjects who took antihypertensive medication at either baseline or follow-up. In the remaining population of 1854 subjects (976 women), systolic $(126 \mathrm{mmHg}(116 ; 138 \mathrm{mmHg})$ vs $126 \mathrm{mmHg}(115 ; 138 \mathrm{mmHg}), P=0.092)$ and diastolic blood pressure $(80 \mathrm{mmHg}(74 ; 87 \mathrm{mmHg})$ vs $80 \mathrm{mmHg}$ (74; $86 \mathrm{mmHg}), P=0.923$ ) as well as pulse pressure $(46 \mathrm{mmHg}(39 ; 54 \mathrm{mmHg})$ vs $45 \mathrm{mmHg}$ (38; $53 \mathrm{mmHg}), P=0.032$ ) were comparable between baseline and follow-up. Both analysis of covariance and Poisson regression failed to reveal a statistical significant association between subclinical hyperthyroidism and blood pressure or hypertension in this subpopulation (Table 4).

Furthermore, we performed sensitivity analyses by including the change in the exposure status as well as change of confounder variables in the multivariable models. All these analyses did not reveal a significant association between subclinical hyperthyroidism and blood pressure-related variables (data not shown).

Table 4 Association between subclinical hyperthyroidism and blood pressure-related variables in subjects without antihypertensive treatment.

\begin{tabular}{lll}
\hline & $\begin{array}{l}\text { Whole population } \\
(n=1854)\end{array}$ & $\begin{array}{l}\text { Disease-free population } \\
(n=1488)\end{array}$ \\
\hline$\beta(95 \%$ confidence interval) & & \\
Systolic blood pressure $(\mathrm{mmHg})$ & $0.89(-1.65$ to 3.42$)$ & $\begin{array}{l}0.62(-4.07 \text { to } 2.52) \\
P=0.645\end{array}$ \\
& $P=0.492$ & $0.64(-1.39$ to 2.62$)$ \\
& $0.99(-0.55$ to 2.53$)$ & 0.547 \\
Diastolic blood pressure $(\mathrm{mmHg})$ & $P=0.207$ & $-1.39(-3.66$ to 0.88$)$ \\
Pulse pressure (mmHg) & $-0.15(-1.90$ to 1.60$)$ & $P=0.230$ \\
& $P=0.866$ & $0.82(0.41$ to 1.65$)$ \\
Relative risk (95\% confidence interval) & & $P=0.578(n=1165)$ \\
Increased systolic blood pressure $\geq 140 \mathrm{mmHg}$ & & $1.06(0.50$ to 2.28$)$ \\
& $1.25(0.83$ to 1.91$)$ & $P=0.874(n=1233)$ \\
Increased diastolic blood pressure $\geq 90 \mathrm{mmHg}$ & $P=0.288(n=1450)$ & $0.73(0.36$ to 1.48$)$ \\
& $1.20(0.67$ to 2.14$)$ & $P=0.381(n=1289)$ \\
Increased pulse pressure $\geq 59 \mathrm{mmHg}$ & $P=0.535(n=153)$ & $0.99(0.55$ to 1.79$)$ \\
& $1.07(0.66$ to 1.73$)$ & $P=0.968(n=1082)$
\end{tabular}

Analysis of covariance for continuous outcome and Poisson regression for dichotomous outcome, adjusted for age, sex, overweight, obesity, smoking status and time between the examinations. Analyses of covariance were additionally controlled for blood pressures at baseline.

a Subjects with prevalent disorder at baseline were excluded from analyses. Numbers of subpopulations are given for each analysis. 
Table 5 Baseline characteristics of the study population compared with non-participants.

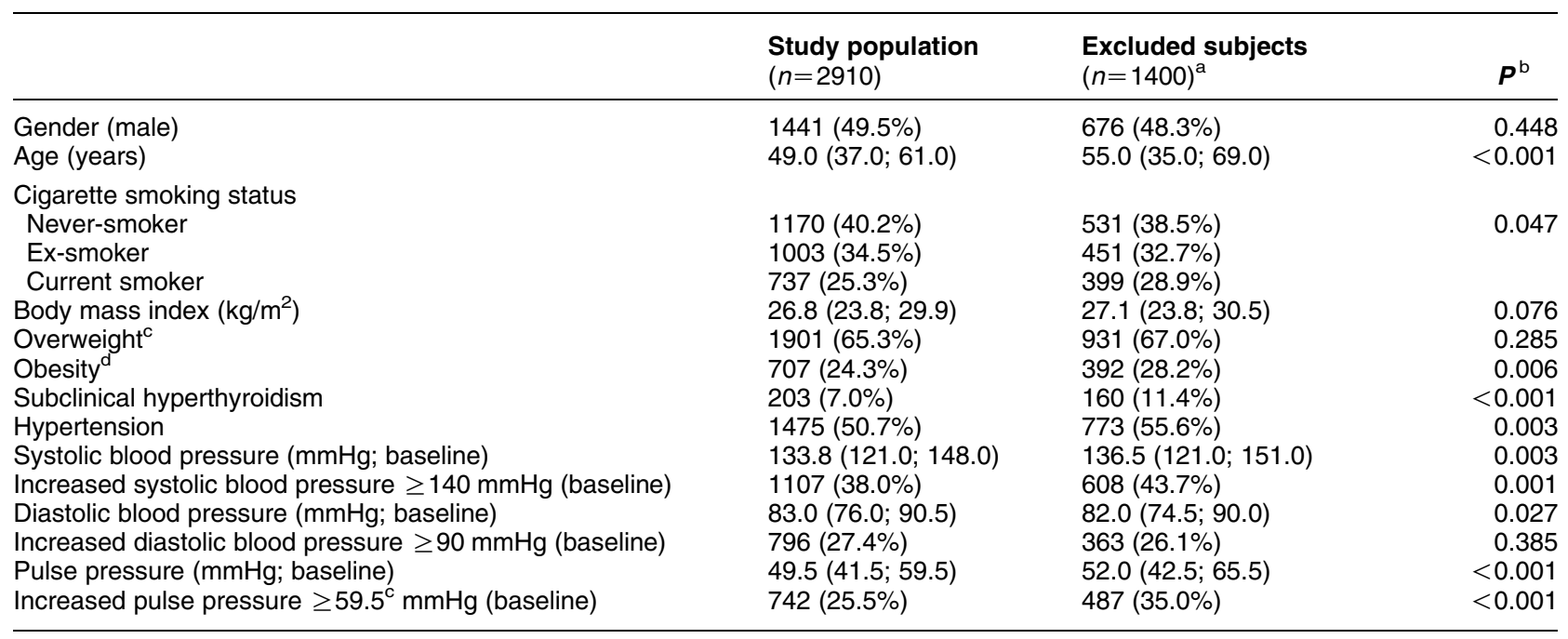

Data are given as numbers (\%) or median (25th and 75th percentile).

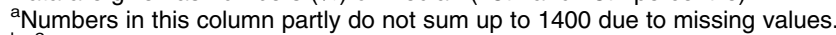

${ }^{b} \chi^{2}$ test (nominal data) or Kruskal-Wallis test (interval data).

'Overweight was defined as body mass index $\geq 25 \mathrm{~kg} / \mathrm{m}^{2}$.

${ }^{\mathrm{d}}$ Obesity was defined as body mass index $\geq 30 \mathrm{~kg} / \mathrm{m}^{2}$.

To assess possible bias due to missing values and loss to follow-up, we compared the study population with subjects who participated in the baseline SHIP-0 examinations but were excluded from the study population (Table 5). Subjects who did not belong to the study population were older, more often current smokers, obese, subclinical hyperthyroid and hypertensive than subjects included in the study population. Also, most of the blood pressure values were higher in the excluded than in the included subjects (Table 5). Accounting for non-response and loss to follow-up by applying statistical weighing factors, we consistently did not detect statistical significant associations between subclinical hyperthyroidism and blood pressure-related variables with one exception. In the whole population, subjects with subclinical hyperthyroidism had higher diastolic blood pressure values than reference subjects (adjusted mean difference $1.49 \mathrm{mmHg}$; 95\% CI 0.22; $2.75 \mathrm{mmHg} ; \mathrm{P}<0.05)$. In the disease-free population, however, this difference did not attain statistical significance anymore (adjusted mean difference $1.32 \mathrm{mmHg}$; $95 \% \mathrm{CI}-0.40 ; 3.40 \mathrm{mmHg} ; P=0.131$ ).

\section{Discussion}

In the present study, we investigated the association between subclinical hyperthyroidism and blood pressure-related variables using data from a prospective population-based cohort study. We found negligible associations between subclinical hyperthyroidism and blood pressure or hypertension. To the best of our knowledge, this is the first time that this issue has been analyzed using longitudinal data.
Our data are in good agreement with the results of a cross-sectional population-based Japanese study that included participants who were not treated for thyroid disease (6). In this study (6), the prevalence of hypertension was similar between 77 subjects with subclinical hyperthyroidism and 3130 subjects with serum TSH levels within the reference range. Our results are also in concordance with findings recently reported from our cross-sectional SHIP data (7). Japan and Germany differ from each other with respect to the iodine supply that is iodine-replete in Japan (17) and formerly iodine-deficient in Germany $(11,18)$. Both countries also differ considerably with respect to the prevalence of hypertension, which is much higher in Japan than in Germany (19). Moreover, within Germany the prevalence of hypertension is highest in the population of West Pomerania (20). The fact that similar results have been obtained from these two distinct populations supports the notion that subclinical hyperthyroidism is not associated with blood pressurerelated variables.

However, the present findings are in contrast to the 1981 Busselton study that was conducted in Australia comprising 2033 participants with subclinical hyperthyroidism who did not have prior thyroid disease (5). The original population comprised 3940 participants corresponding to a response proportion of $64 \%$. Unfortunately, blood samples were only available in $\sim 50 \%$ of the subjects (21). Thus, it cannot be fully ruled out that selection might partly explain the differences in the results between our investigation and the Busselton study (5). The present cohort study may be regarded as an extension of our recent analyses 
from the cross-sectional data (7). Against this background longitudinal data are needed from studies that have cross-sectionally demonstrated an association between subclinical hyperthyroidism and hypertension.

Current guidelines recommend that subclinical hyperthyroidism should be defined as a serum TSH concentration below the statistically defined lower limit of the reference range when serum $\mathrm{FT}_{4}$ and $\mathrm{T}_{3}$ concentrations are within their reference ranges $(9,22)$. In our study, we followed this recommendation with the exception that we used serum $\mathrm{FT}_{3}$ instead of $\mathrm{T}_{3}$ levels for definition. The lower serum TSH reference value of $0.25 \mathrm{IU} / \mathrm{ml}$ established for our study region (14) is lower than values analyzed from other studies (23-25). Different iodine supplies mainly account for this discrepancy (14). For the present study, a relatively low TSH cut-off might be more appropriate than a higher TSH cut-off since the low cut-off increases the specificity of the definition of subclinical hyperthyroidism. To further increase this specificity, we repeated all multivariable analyses by applying a TSH cut-off of $0.1 \mathrm{IU} / \mathrm{ml}$ to define subclinical hyperthyroidism. These analyses confirmed the major results, i.e. subclinical hyperthyroidism was not associated with blood pressure or hypertension.

The lowering of the blood pressure cut-offs for the definition of hypertension at the end of the 1990s has led to an increase in antihypertensive treatment for the past 10 years (26). During follow-up, we observed a decrease in median blood pressure in the whole population. This decrease was no longer present for systolic and diastolic blood pressure when all subjects with antihypertensive medication were excluded from the analyses. Only the small difference in pulse pressure of $1 \mathrm{mmHg}$ attained statistical significance due to the large number of participants. These data suggest that at follow-up hypertension has been treated more vigorously and antihypertensive treatment has been initiated at lower blood pressure levels than at baseline.

The likelihood that measuring error by intraindividual variation of blood pressure lowers the precision in the classification of the dependent variable is higher in follow-up studies than in cross-sectional studies. We attempted to tackle this problem by using standardized protocols for blood pressure measurements at baseline and follow-up. We took blood pressure readings thrice after sufficient rest periods and used only the second and the third readings for statistical analyses. Although we detected all expected risk factors for hypertension in our data, we cannot unequivocally exclude that we missed a weak association between subclinical hyperthyroidism and hypertension due to blood pressure variations.

Subjects who were excluded from the study population due to missing values or loss to follow-up were older than the subpopulation studied in the present investigation. Consequently, the former had more common baseline subclinical hyperthyroidism and hypertension than the latter. Furthermore, as in other population-based studies, health problems were a major reason for non-participation in baseline SHIP-0 (3). To account for these imbalances we introduced weighing factors and repeated all multivariable analyses. These analyses revealed a weak, albeit statistically significant association between subclinical hyperthyroidism and diastolic blood pressure. However, this association was in a biologically implausible direction and present neither in the disease-free subpopulation nor for all other blood pressure-related end points including the dichotomized increased diastolic blood pressure variable. Based on these results, we have no strong indication for the presence of a strong response bias in the present analyses.

We conclude that subclinical hyperthyroidism is not associated with changes in blood pressure, pulse pressure or incident hypertension.

\section{Declaration of interest}

The funding sources did not contribute to study design in the collection, analysis and interpretation of data; in the writing of the report; and in the decision to submit the article for publication. There are no conflicts of interest.

\section{Funding}

The work is part of the Community Medicine Research net (CMR) of the University of Greifswald, Germany, which is funded by the Federal Ministry of Education and Research, the Ministry of Cultural Affairs as well as the Social Ministry of the Federal State of Mecklenburg-West Pomerania. The CMR encompasses several research projects, which are sharing data of the population-based Study of Health in Pomerania (SHIP; http://www.community-medicine.de). Analyses were further supported by a grant of the German Research Foundation (DFG Vo 955/5-1).

\section{References}

1 Coban E, Aydemir M, Yazicioglu G \& Ozdogan M. Endothelial dysfunction in subjects with subclinical hyperthyroidism. Journal of Endocrinological Investigation 200629 197-200.

2 Tamer I, Sargin M, Sargin H, Seker M, Babalik E, Tekce M \& Yayla A. The evaluation of left ventricular hypertrophy in hypertensive patients with subclinical hyperthyroidism. Endocrine Journal $2005 \mathbf{5 2} 421-425$.

3 Volzke H, Robinson DM, Schminke U, Ludemann J, Rettig R, Felix SB, Kessler C, John U \& Meng W. Thyroid function and carotid wall thickness. Journal of Clinical Endocrinology and Metabolism $2004892145-2149$.

4 Cappola AR, Fried LP, Arnold AM, Danese MD, Kuller LH, Burke GL, Tracy RP \& Ladenson PW. Thyroid status, cardiovascular risk, and mortality in older adults. Journal of the American Medical Association 2006295 1033-1041.

5 Walsh JP, Bremner AP, Bulsara MK, O'Leary P, Leedman PJ, Feddema P \& Michelangeli V. Subclinical thyroid dysfunction and blood pressure: a community-based study. Clinical Endocrinology $2006 \mathbf{6 5} 486-491$.

6 Takashima N, Niwa Y, Mannami T, Tomoike H \& Iwai N. Characterization of subclinical thyroid dysfunction from cardiovascular and metabolic viewpoints: the Suita study. Circulation Journal 200771 191-195. 
7 Volzke H, Alte D, Dorr M, Wallaschofski H, John U, Felix SB \& Rettig R. The association between subclinical hyperthyroidism and blood pressure in a population-based study. Journal of Hypertension 200624 1947-1953.

8 Gharib H, Tuttle RM, Baskin HJ, Fish LH, Singer PA \& McDermott MT. Subclinical thyroid dysfunction: a joint statement on management from the American Association of Clinical Endocrinologists, the American Thyroid Association, and the Endocrine Society. Journal of Clinical Endocrinology and Metabolism 200590 581-585 (discussion 586-587).

9 Surks MI, Ortiz E, Daniels GH, Sawin CT, Col NF, Cobin RH, Franklyn JA, Hershman JM, Burman KD, Denke MA, Gorman C, Cooper RS \& Weissman NJ. Subclinical thyroid disease: scientific review and guidelines for diagnosis and management. Journal of the American Medical Association $2004291228-238$.

10 John U, Greiner B, Hensel E, Ludemann J, Piek M, Sauer S, Adam C, Born G, Alte D, Greiser E, Haertel U, Hense HW, Haerting J, Willich S \& Kessler C. Study of Health in Pomerania (SHIP): a health examination survey in an east German region: objectives and design. Sozial- und Präventivmedizin $20014 \mathbf{4 6}$ 186-194.

11 Volzke H, Ludemann J, Robinson DM, Spieker KW, Schwahn C, Kramer A, John U \& Meng W. The prevalence of undiagnosed thyroid disorders in a previously iodine-deficient area. Thyroid 200313 803-810.

12 Haring R, Alte D, Volzke H, Sauer S, Wallaschofski H, John U \& Schmidt CO. Extended recruitment efforts minimize attrition but not necessarily bias. Journal of Clinical Epidemiology 200962 252-260.

13 Volzke H, Haring R, Schmidt CO, Alte D, Kramer A, Hoffmann W, John U \& Wallaschofski H. Does response bias influence population studies of thyroid disorders? Thyroid 200818 873-878.

14 Volzke H, Alte D, Kohlmann T, Ludemann J, Nauck M, John U \& Meng W. Reference intervals of serum thyroid function tests in a previously iodine-deficient area. Thyroid $200515279-285$.

15 Kindler S, Roser M, Below H, Hoffmann W, Kohlmann T, Kramer A, Kirsch G \& Volzke H. Thyroid disorders in employees of a nuclear power plant. Thyroid 200616 1009-1017.

16 Zou G. A modified poisson regression approach to prospective studies with binary data. American Journal of Epidemiology 2004 $159702-706$.

17 Konno N, Makita H, Yuri K, Iizuka N \& Kawasaki K. Association between dietary iodine intake and prevalence of subclinical hypothyroidism in the coastal regions of Japan. Journal of Clinical Endocrinology and Metabolism 199478 393-397.

18 Thamm M, Ellert U, Thierfelder W, Liesenkotter KP \& Volzke H. Iodine intake in Germany. Results of iodine monitoring in the
German Health Interview and Examination Survey for Children and Adolescents (KiGGS). Bundesgesundheitsblatt, Gesundheitsforschung, Gesundheitsschutz 200750 744-749.

19 Stehle G, Hinohara S, Cremer P, Feng Z, Bernhardt R, Dempfle CE, Goto Y, Seidel D, Heene DL \& Schettler G. Risk factor patterns for coronary heart disease in China, Japan and Germany. Chinese Medical Journal 1992105 356-359.

20 Meisinger C, Heier M, Volzke H, Lowel H, Mitusch R, Hense HW \& Ludemann J. Regional disparities of hypertension prevalence and management within Germany. Journal of Hypertension 200624 293-299.

21 Walsh JP, Bremner AP, Bulsara MK, O'Leary P, Leedman PJ, Feddema P \& Michelangeli V. Parity and the risk of autoimmune thyroid disease: a community-based study. Journal of Clinical Endocrinology and Metabolism 200590 5309-5312.

22 Ross DS. Serum thyroid-stimulating hormone measurement for assessment of thyroid function and disease. Endocrinology and Metabolism Clinics of North America 200130 245-264.

23 Hollowell JG, Staehling NW, Flanders WD, Hannon WH, Gunter EW, Spencer CA \& Braverman LE. Serum TSH, T(4), and thyroid antibodies in the United States population (1988 to 1994): National Health and Nutrition Examination Survey (NHANES III). Journal of Clinical Endocrinology and Metabolism 200287 489-499.

24 Eskelinen S, Suominen P, Vahlberg T, Lopponen M, Isoaho R, Kivela SL \& Irjala K. The effect of thyroid antibody positivity on reference intervals for thyroid stimulating hormone (TSH) and free thyroxine $\left(\mathrm{FT}_{4}\right)$ in an aged population. Clinical Chemistry and Laboratory Medicine 200543 1380-1385.

25 Jensen E, Hyltoft Petersen P, Blaabjerg O, Hansen PS, Brix TH, Kyvik KO \& Hegedus L. Establishment of a serum thyroid stimulating hormone (TSH) reference interval in healthy adults. The importance of environmental factors, including thyroid antibodies. Clinical Chemistry and Laboratory Medicine $2004 \mathbf{4 2}$ 824-832.

26 Ostchega Y, Dillon CF, Hughes JP, Carroll M \& Yoon S. Trends in hypertension prevalence, awareness, treatment, and control in older U.S. adults: data from the National Health and Nutrition Examination Survey 1988 to 2004. Journal of the American Geriatrics Society 200755 1056-1065.

27 Stang A \& Jockel KH. Studies with low response proportions may be less biased than studies with high response proportions. American Journal of Epidemiology 2004159 204-210.

Received 25 June 2009

Accepted 6 July 2009 